\title{
MEM/PORTUGAL SENTIDOS E SIGNIFICADOS DE UMA (AUTO)FORMAÇÃO COOPERADA ENTRE PROFESSORES
}

\author{
SCHOOL AND EDUCATION AS SPACES OF (RE) SOCIAL SIGNIFICANCE: (RE) \\ READINGS FROM MEM / PORTUGAL
}

Tânia Serra Azul Machado Bezerra ${ }^{1}$

Pedro Francisco Gonzalez ${ }^{2}$

RESUMO

Rui Trindade ${ }^{3}$

Este texto constitui resultado de investigação vivenciada no pós-doutoramento em Ciências da Educação da Universidade do Porto e, intenciona demonstrar, vivências docentes que relacionam as categorias Formação Integral, Aprendizagem Cooperativa, Inovação/Diferenciação Pedagógica e Escola, com amparo em experiências de professores do MEM/Portugal. Objetiva-se debater e analisar, com base nas ações pedagógicas mencionadas, o processo constituidor de uma formação humana que reflete os sujeitos em sua integralidade, autonomia e emancipação. Também se objetiva compreender ações e relações pedagógicas cotidianas que configuram uma cultura docente de (re)invenção da escola a partir de contextos de inovação. Metodologicamente, trata-se de uma pesquisa qualitativa pautada em análises dialógicas em que foram associadas fontes orais e escritas, no sentido de movimentar-se do específico ao geral, ou seja, das particularidades do objeto para a compreensão de um todo complexo, que são as categorias Escola e Docência, em vivência de uma proposta de educação que subverte a lógica do instrumentalismo e tecnicismo. Em hipóteses conclusivas, significam contato denso com outra abordagem à instituição escola sob um viés de ruptura com a tendência normativa e positivista. Isto se coloca, finalmente, no sentido de ampliar espaços de debates e aprofundamentos teóricos e práticos acerca do magistério e da Escola como lugar/tempo de ciência/pesquisa e possibilidade de contribuir com a produção de novos sentidos/significados sociais.

PALAVRAS-CHAVE: escola; MEM; docência; inovação

\begin{abstract}
This text is a result of research carried out in the postdoctoral studies in Educational Sciences of the University of Porto and, intends to demonstrate, teacher experiences that relate the categories Integral Training, Cooperative Learning, Innovation / Pedagogical Differentiation and School, supported by experiences of teachers of the MEM / Portugal. The objective is to discuss and analyze, based on the pedagogical actions mentioned, the process that constitutes a human formation that reflects the subjects in their integrality, autonomy and emancipation. It also aims to understand everyday pedagogical actions and relationships that shape a teaching culture of (re) invention of the school from contexts of innovation. Methodologically, this is a qualitative research based on dialogical analysis in which oral and written sources have been

\footnotetext{
${ }^{1}$ Professora Adjunta da Universidade Estadual do Ceará. Doutora em Educação Brasileira pela UFC. Pesquisadora do LABOR/UFC e EIP/UP. taniasamb@hotmail.com

${ }^{2}$ Professor da Unidade dos Açores. Doutor em Ciências da Educação pela Universidade de Salamanca. Membro do MEM/Portugal. pedro.f.gonzalez@uac.pt

${ }^{3}$ Professor Assistente da Universidade do Porto. Doutor em Ciências da Educação pela Universidade do Porto. Coordenador e pesquisador do EIP/UP. trindade@ fpce.up.pt
} 
associated, in the sense of moving from the specific to the general, that is, from the particularities of the object to the comprehension of a complex whole, which are the categories School and Teaching, in the experience of a proposal of education that subverts the logic of instrumentalism and technicalism. In concluding hypotheses, they mean dense contact with another approach to the school institution under a bias of rupture with the normative and positivist tendency. Finally, the aim is to broaden the scope of debates and theoretical and practical insights about teaching and the School as a place / time for science / research and the possibility of contributing to the production of new meanings / social meanings.

KEYWORDS: school; MEM; teaching; innovation

\title{
1 INTRODUÇÃO
}

\begin{abstract}
"Sou professor a favor da esperança que me anima apesar de tudo. Sou professor contra o desengano que me consome e imobiliza. Sou professor a favor da boniteza de minha própria prática, boniteza que dela some se não cuido do saber que devo ensinar, se não brigo por este saber, se não luto pelas condições materiais necessárias sem as quais meu corpo, descuidado, corre o risco de se amofinar e de já não ser testemunho que deve ser de lutador pertinaz, que cansa, mas não desiste." (FREIRE, 2011, p.115-6).
\end{abstract}

É sobre uma experiência docente prenhe de esperança, como pensa Freire acima, que escrevemos esse texto. As análises e os relatos organizados ao longo do escrito depõem sobre o Movimento da Escola Moderna em Portugal - MEM/Portugal. Espaço com docentes que, em nossa interpretação do fenômeno, são tanto a favor quanto construtores da boniteza de uma práxis docente diferenciada e pautada em uma compreensão coletiva e emancipadora de sociedade. Referidos docentes vivenciam tempos sistemáticos de trocas e mediações de experiências e, engajados numa proposta inovadora de educação, organizam ações cotidianas de/em sala de aula, a partir de espaços de estudos e planejamento baseados em grupos cooperativos $^{4}$ de professores e de discentes.

Sobre o MEM/Portugal:

No modelo pedagógico do MEM estão ligados inextrincavelmente o modelo curricular e o modelo de formação profissional (a auto-formação cooperada). Mesmo na representação que a comunidade profissional faz do MEM o movimento associativo em torno da formação é tão importante como o modelo curricular Assim, à dupla mediação - a mediação do educador que promove a participação guiada das crianças - deve juntar-se uma outra instância de mediação - a dos professores membros do Movimento. É esta outra mediação que regula, interpreta e reinterpreta a gramática pedagógica que vai regendo a acção do Movimento, dos profissionais e das crianças. (FORMOSINHO, 2003, p. 08).

\footnotetext{
${ }^{4}$ Grupos cooperativos porque exercem um trabalho coletivo horizontal em que todos os membros do grupo: discentes e docentes possuem função e participação ativa na produção e planejamento do conhecimento.
} 
Temos, por conseguinte, uma comunidade organizada em torno da aprendizagem centrada no grupo, ou melhor, nos grupos, e assim se dá a formação profissional (entre professores), na sala de aula. Isto também ocorre através de espaços/tempos de debates e trocas de experiências para o planejamento DO QUE e COMO será trabalhado, cada conteúdo e cada dificuldade, individual e/ou coletiva. Folque (2014) considera os seguintes fatores para uma reconstrução da cultura escolar a partir da cooperação: participação ativa dos atores sociais em cada decisão, tomada de consciência sobre dificuldades sociais e cognitivas, organização de conteúdos e temáticas centradas nos limites e possibilidades de cada grupo, debate sistemático sobre limites e possibilidades cotidianas e a compreensão da educação como espaço heterogêneo e atravessado pela diversidade.

Estes preceitos adotados pelo MEM/Portugal, buscam uma (re)invenção da escola como essa tem tradicionalmente se estabelecido e sido apropriada pela lógica neoliberal. Organizar-se em torno de grupos professor/professor, discente/discente, professor/discente, com a proposta de respeito a autonomia individual e coletiva, com a aplicação de processos de uma democracia direta ${ }^{5}$, constitui ruptura com o positivismo educacional. E é assim que nasce nosso interesse investigativo para o pós-doutorado, com a necessidade de apreender no tecido das referidas relações educacionais, sociais, políticas e culturais, as vivências docentes que relacionam as categorias Formação Integral, Aprendizagem Cooperativa, Cultura de Resistência e Escola, com base em experiências de formação de professores do MEM/Portugal. Sobre os aspectos metodológicos,

\begin{abstract}
a questão que temos imediatamente à nossa frente não é a dos limites da experiência, mas a maneira de alcançá-la, ou produzí-la. A experiência surge espontaneamente no ser social, mas não surge sem pensamento. Surge porque homens e mulheres (e não apenas filósofos) são racionais, e refletem sobre o que acontece a eles e ao seu mundo. (THOMPSON, 1981, p. 16).
\end{abstract}

Assim é que apreendemos a experiência histórico-educativa vivenciada por docentes e discentes tocados pelo MEM que, em nossa compreensão, constitui terra fértil para um viés mais humanizado de escola e aprendizagem, sobretudo ao considerarmos que tais sujeitos em formação, "refletem sobre o que acontece a eles e ao seu mundo" (THOMPSON, 1981, p. 16), na condição de pessoas engajadas em prol de uma educação que leve à reflexão/transformação, à compreensão de si, do outro e do mundo. Assim como anotam Trindade e Cosme,

\footnotetext{
${ }^{5} \mathrm{O}$ conceito de democracia direta é exercido no sentido da participação horizontal, autônoma e ativa de todos os membros da comunidade educativa que envolve o MEM.
} 
Não é possível abordar-se o acto de educar ou o actor de aprender no âmbito das escolas como actos dissociados dos compromissos políticos, culturais e formativos que justificam a sua existência como um espaço singular de socialização (...). (2010, p. 17).

Compreendemos, com efeito, a escola como um espaço/tempo historicamente situado e politicamente cultivado (TRINDADE e COSME, 2010), pois como qualquer outra instância social, ela é permeada, dialeticamente, pelas diversas relações/produções humanas. $\mathrm{Na}$ apropriação deste fenômeno, no que se refere ao procedimento metodológico, estruturamos esse texto em dois momentos: um primeiro que traz breve relato sobre o Movimento, incluindo seu surgimento, concepção de escola e sociedade, proposta política e pedagógica e (auto) formação de professores e, um segundo, em que teceremos análises a partir de relatos de professores, no cruzamento de fontes empíricas e bibliográficas, para a produção de sentidos e significados de uma (auto)formação cooperada.

Buscamos analisar/relacionar produções e pesquisas diversas sobre o MEM/Portugal, resultados dos encontros nacionais e regionais do movimento, além de outras publicações que dissertassem sobre tal experiência política e pedagógica, bem como compusessem interlocução com nossas categorias de análise - Formação Integral, Aprendizagem Cooperativa, Cultura de Resistência e Escola). Investimos ainda na coleta de narrativas de professores do MEM/Portugal e assistimos durante todo o ano letivo 2017/2018 os sábados pedagógicos do MEM/Porto.

A coleta e o registro das narrativas, bem como a observação dos espaços formativos, foram tratadas como fontes empíricas para análises, percebendo-as como espaço/tempo de contradições,

[...] admitamos, simultaneamente, que o pensamento humano busca a verdade através das contradições e que as contradições têm um sentido objetivo, uma fundamentação na realidade. Cessamos de rejeitar como aparentes ou absurdas todas as contradições; justamente ao contrário, colocamos no centro das preocupações a pesquisa das contradições e de seus fundamentos objetivos. (LEFEBVRE, 2009, p.29).

Nesse campo híbrido e contraditório, importa destacar que as observações e análises dos inquéritos ${ }^{6}$ acontecem no sentido de perceber limites e possibilidades do Movimento no contexto da escola Portuguesa. Como também, perceber a complexidade dos inúmeros elementos gradativamente revelados para análise, que vão desde o contexto político e

\footnotetext{
${ }^{6}$ Compartilhamos, por e-mail, um inquérito, respondido por onze professores do MEM (Lisboa, Paços de Ferreira, Praia de Vitória, Angra do Heroísmo, Ponta Delgada, Paredes, Lousada e Porto), este problematizou sobre as propostas/práticas pedagógicas do Movimento, como também sobre as experiências profissionais de cada um diante do engajamento com o MEM.
} 
pedagógico até as características peculiares ao grupo: sua dinâmica em sala de aula, o envolvimento com a comunidade, a organização social do trabalho escolar, ritmos, tempos e possibilidades de inovação pedagógica destinada à autonomia e à emancipação.

Nessa perspectiva, procuramos registrar e exprimir como lócus de reflexão a óptica e a versão das experiências destes agentes educacionais destacados para a

Escola como uma organização educativa que não poderá deixar de ser abordada como uma organização subordinada a compromissos de natureza política e cultural que, de algum modo, a transcendem e que, por isso, não poderão ser ignorados ou iludidos quando a abordamos como instituição educativa. (TRINDADE e COSME, 2010, P. 18).

Tal procedimento metodológico percebe as relações específicas do objeto de estudo em conexão com uma realidade ampla e complexa. Vislumbra analisar/registrar o MEM, compreendendo como os princípios da cooperação e autonomia podem (re)contar e subverter ações docentes-discentes em tempos neoliberais. Neste movimento, de substrato em substrato, buscamos compreender a proposta de formação integral e aprendizagem cooperativa do MEM/Portugal sob distintos níveis e de maneira heterogênea, vinculando-se às experiências reais de cada sujeito, suas possibilidades de compreender o mundo e as muitas contradições enfrentadas cotidianamente, perante avanços e retrocessos. Assim como na escola, cada um aprende sob determinada singularidade, fatores que não desmerecem os espaços coletivos e os princípios emancipatórios.

[...] as contradições do pensamento e das consciências subjetivas dos homens apresentam um fundamento objetivo e real. Se existem "pró e contra", "sim e não", é porque as realidades apresentam não somente aspectos múltiplos, mas facetas mutáveis e contraditórias. Desse modo, o pensamento humano, que não consegue captar de uma só vez as coisas reais, se vê obrigado a tatear e caminhar através de suas próprias dificuldades e contradições até atingir as realidades movediças e instáveis e as contradições reais. (LEFEBVRE, 2009, p.28-29).

Observar e ouvir professores do MEM/Portugal, compreendendo que as relações sociais são fortemente tocadas pelo princípio da contradição, é admitir que as ações desenvolvidas, as relações vivenciadas, as narrativas e observações coletadas possuem limites claramente humanos; e, portanto, precisam ser analisadas diante de um contexto historicamente situado, levando-se em consideração suas dificuldades econômicas e políticas, suas polêmicas estruturais e culturais.

\section{COOPERAÇÃO, PARTICIPAÇÃO E A CONTRAHEGEMONIA NEOLIBERAL}


Apresentamos neste tópico uma brevíssima resenha histórica sobre a evolução de conceitos desta proposta de organização da formação e da pedagogia que se tem vindo a desenvolver sob o chapéu do Movimento da Escola Moderna. As reflexões foram sistematizadas a partir de elementos como: surgimento, concepção de escola e sociedade, proposta política e pedagógica e (auto)formação de professores.

Ainda continuamos a considerar a influência de Celestin Freinet nas bases dessa pedagogia. Sujeitas à reflexão e à experiência em contextos ao longo do tempo, as ideias iniciais de Freinet foram avançando, graças à reflexão cooperada, para a estrutura ou modelo pedagógico que hoje conhecemos em Portugal. Alguns valores, subjacentes à cooperação, à expressão livre, têm persistido e são hoje tão atuais como nos seus inícios. É dizer, hoje podemos "dizer melhor a nossa palavra", no vocabulário de Paulo Freire (1989). Podemos dizer melhor "porque fazemos o que fazemos" no quotidiano escolar e na formação dos nossos pares.

As técnicas Freinet, graças à reflexão e à troca sistemática de experiências do cotidiano profissional, foram se transformando para a construção de estratégias traduzidas em técnicas, metodologias, atividades, instrumentos, recursos, etc, associados a valores e conceitos caros às sociedades democráticas, como a participação, a autonomia e o sentido crítico, por exemplo. A esse respeito, complementa Niza (1997, p.34) “uma interacção dialéctica onde a prática faz apelo à teoria para que a prática se aperfeiçoe e desenvolva por sucessivos e interpolados momentos de teorização, enquadramento ou confronto teórico, conforme as situações e as necessidades de percurso da acção e do conhecimento."

O Movimento da Escola Moderna português não renega seu passado freinetiano. Fez avançar essa proposta, alargou-a, atualizou-a, enriqueceu-a em diálogo permanente com a realidade contemporânea e com a reflexão sistemática das ações docentes. As "assembleias" originais de Freinet foram se metamorfoseando para o "Conselho", como matriz democrática da organização social das aprendizagens. Mesmo os instrumentos de organização e avaliação, como os planos individuais de trabalho, beneficiaram de um avanço sustentado na reflexão cooperada e hoje procuram responder melhor às necessidades das crianças, ao mesmo tempo que propiciam o desenvolvimento do sentido de autoavaliação das mesmas.

Não são técnicas que podem se comprar feitas. É preciso, pela heterogeneidade de cada realidade escolar, a implicação do docente na sua concessão, na sua elaboração e na sua utilização, de acordo com o seu itinerário pessoal e com a realidade em que se insere. É preciso transformá-las, reconstruí-las permanentemente no sentido que Brunner (1969) reconhece o 
conceito de transformação "os meios pelos quais lidamos com a informação, de modo a irmos além dela". (p. 67). Segundo Niza (1997), sobre a organização social do trabalho no MEM:

(...) o ponto central do sistema corresponde porém a um princípio de ética pedagógica enunciado a partir das práticas do Movimento da Escola Moderna (MEM) e que servem à intervenção educativa como a qualquer outra intervenção social: "os meios formativos têm de veicular os fins Democráticos da Formação" e " os Processos de Formação têm que reproduzir os processos sociais autênticos de construção dos saberes científicos, técnicos ou artísticos". (p 20).

Nos últimos anos, pela força da ideologia dominante e influência neoliberal, narrativas e agendas que valorizam a dimensão mais humana e democrática da nossa sociedade foram perdendo espaço e força. Nesse contexto, precisamos reconsiderar a significação, reforçando o seu sentido primigênio de conceitos, como a cooperação, como valor e como conceito transversal e estruturante, na educação, na formação e na sociedade. Incluímos também nesta análise o conceito de participação que, em democracia direta, não pode ser reduzido apenas ao ato de votar.

$\mathrm{Na}$ sequência desta reflexão sobre os conceitos e valores que entendemos fundamentais em qualquer democracia participativa, devemos repensar o papel da escola e da educação organizadas para responder às necessidades de um mundo pensado, neste momento, infelizmente, por e para a economia neoliberal. Torna-se inadiável a construção de espaços de resistência aos preceitos do mercado que fazem da escola palco de consumismo, competição, meritocracia e exclusão. A Educação moldada a tais interesses, omite-se na abertura de espaços críticos, reproduzindo conceitos estipulados para a obediência e a mecânica instrução. Negligencia, portanto, uma formação voltada ao enriquecimento das habilidades autônomas, subjetivas e criativas das pessoas, trabalha com vistas a objetivar e dogmatizar seus conhecimentos e reforça:

[...] toda a perspectiva meritocrática dentro do processo escolar. Assim como no mundo da produção todos os homens são "livres" para ascenderem socialmente, e esta ascensão depende única e exclusivamente do esforço, da capacidade, da iniciativa, da administração racional dos seus recursos, no mundo escolar a não aprendizagem, a evasão, a repetência são problemas individuais. Trata-se da falta de esforço, da "não aptidão", da falta de vocação. Enfim, a ótica positivista que a teoria do capital humano assume no âmbito econômico justifica as desigualdades de classe, por aspectos individuais; no âmbito educacional, igualmente mascara a gênese da desigualdade no acesso, no percurso e na qualidade que têm as classes sociais. (FRIGOTTO, 2010, p. 80).

Compreendemos a necessidade de subversão dessa lógica. Como refere Sérgio Niza (1996, p.08), “Os meios devem veicular em si os fins democráticos que se propõem”. A escola 
que o MEM vem construindo é um instrumento da sociedade democrática, da "polis", para a sua consolidação e expansão. Por isso, a escola e a educação são instrumentos intrinsecamente políticos. São meios de transformação da sociedade. A proposta do MEM é uma proposta política, que visa uma transformação social através da pedagogia e da intervenção com o professor.

Quando falamos em cooperação e participação na escola, estamos a pensar em formas de organização social das atividades para aprender em contexto alargado. Assim, só tem sentido falarmos em cooperação e participação quando essas impregnam a cultura da escola, contaminam a organização da escola e são intrínsecas às estratégias de que nos socorremos no nosso cotidiano escolar. Cooperar é pensarmos em conjunto, “co-operar”, para Piaget (1970). Cooperar é projetarmos em conjunto, é aprendermos em conjunto.

O MEM percorreu um longo caminho para a fundamentação da prática da formação e da prática pedagógica através da reflexão em cooperação. $\mathrm{O}$ desenvolvimento profissional do professor do MEM decorre da reflexão e procura obsessiva de coerência da sua prática pedagógica e da formação com os princípios que defende. A relação entre a construção da sua formação e da pedagogia que desenvolve no cotidiano se evidencia no conceito de isomorfismo, não apenas no plano dos princípios mas também das estratégias para as tornar concreta. Da mesma maneira que os profissionais da educação se formam em pares, assim eles organizam as atividades de aprendizagens para os alunos/crianças. Na cooperação, pela participação, na expressão livre. Sobre a estratégia pedagógica isomórfica, assinala Niza (1997) como:

(...) uma estratégia geral de formação baseada no princípio do isomorfismo pedagógico, metodologia que consiste em experienciar, através de todo o processo de formação, as atitudes, métodos, capacidades e modos de organização que se pretende que venham a ser desempenhados nas práticas profissionais. (p. 43).

Como síntese podemos voltar a sublinhar a necessidade de partir dos conceitos de cooperação (co-operar, pensar e agir, com o outro) e de participação (como intervenção social) que se evidenciam na prática pedagógica e da formação do MEM. Importa termos presente que a filosofia neoliberal tem tergiversado o sentido da educação democrática, e para todos, substituindo-a por outras leituras mais mesquinhas e egoístas.

Por isso, é fundamental sublinhar a importância e atualidade dos conceitos de cooperação e participação, neste momento singular da história, dominado por outros valores como a meritocracia, o lucro, a verticalidade da organização social, etc. É necessário não esquecermos os vários níveis e dimensões do conceito de cooperação: na organização 
cooperativa do trabalho de aprender e no impregnar a cultura da sala/escola com o espírito cooperativo.

Nessa linha de cooperação, e num plano mais concreto, sublinhamos a importância da participação na organização do trabalho de aprender em que as crianças e alunos se implicam nas várias dimensões possíveis, como seja na planificação do que fazer e do que aprender, no desenvolvimento dos trabalhos de aprender e na avaliação do que se faz para aprender, na organização da sala, na gestão conjunta das relações humanas na sala e na escola.

\section{UM OLHAR SOBRE O MEM A PARTIR DOS SÁBADOS PEDAGÓGICOS}

Neste espaço do texto trataremos de nossas observações, análises e relatos extraídos dos sábados pedagógicos do MEM/Porto, espaço formativo que observamos/registramos de outubro/2017 a maio/2018 e com o qual muito aprendemos sobre autoformação cooperada de professores. A esse respeito, a primeira indagação que permeia nossa intenção investigativa é: o que alimenta a disposição desse coletivo de professores, após uma semana de trabalho cansativa, dedicar parte do sábado para o MEM?

Hoje conseguimos essa resposta com segurança. O engajamento político e pedagógico com uma concepção de escola, de educação e de mundo, capaz de tornar a comunidade um espaço mais humanizado, consciente, cooperativo, autônomo e responsável com a vida em sociedade, é o que, em nossa análise do fenômeno, move referido grupo docente. Ressalta uma professora durante debate "escolhemos uma proposta pedagógica que acreditamos e a defendemos, lutamos por ela. Queremos trabalhar, mas com sentido." (DIÁRIO DE CAMPO, 25/11/2017).

O relato da professora faz referência ao desafio que significa, na contracorrente de um contexto tradicional de ensino, optar por uma perspectiva emancipadora de educação que tem como princípio o respeito ao grupo e suas decisões, ao lugar/tempo do outro, ao diverso e ao contraditório, proposta que considera os sujeitos da comunidade em aprendizagem, como capazes de construir, autonomamente, o percurso escolar e social. Os sábados pedagógicos funcionam também como espaço de desabafo e troca de experiências para que sintam apoiados nessa opção pelo modelo/militância do MEM.

No auditório (FPCEUP $)^{7}$, os professores fazem intervenções, socializam experiências exitosas ou não, e compartilham, por exemplo, perseguições por parte da 
administração da escola quando essa discorda do projeto do MEM. Também relatam dificuldades na execução de uma prática pedagógica que está para além do currículo oficial. Todavia, reafirmam suas certezas, pontua uma professora:

\begin{abstract}
Vou lutar por isto porque assim o decidi, mas não há acolhimento nisto. Mas, estou segura diante do (grupo) cooperativo, do que fazemos, mesmo não estando dentro do currículo oficial continuaremos fazendo. Se conseguirmos mudar as leis, ótimo, mas se não conseguirmos, seremos criativos e construiremos outros percursos. (DIÁRIO DE CAMPO, 25/11/2017).
\end{abstract}

Em análise da narrativa acima é possível perceber que o MEM, além de uma opção pedagógica é, sobretudo, uma posição política, comprometida com uma escola que possa romper com a exclusão e a segregação historicamente impostas ao campo educacional. A associação Escola X Estado, no caso português, entre outros aspectos, por exemplo, ocorre no sentido de favorecer/conservar uma sociedade dividida em classes, pautada na desigualdade social e nas demandas de um mercado neoliberal. Sobre essa compreensão de uma escola que não está apartada das dimensões políticas e culturais ressaltam Trindade e Cosme:

A afirmação política e social da Escola não admite leituras casuísticas ou
descontextualizadas da realidade, até porque, para além das razões enunciadas, há que
valorizar dois tipos de factores invariantes que, pese as singularidades das situações e
das conjunturas históricas em presença, contribuem para que possamos compreender
melhor a Escola como uma organização educativa que não poderá deixar de ser
abordada como uma organização subordinada a compromissos de natureza política e
cultural que, de algum modo, a transcendem e que, e que, por isso, não poderão ser
ignorados ou iludidos quando a abordamos como instituição educativa. (2010, p. 18).

Dito isto, importa destacar que o contexto social, político e cultural em que está inserido o MEM carrega as contradições de um sistema que destina a escola um papel de subsunção aos preceitos economicamente hegemônicos do Estado. Entretanto, a organização dos professores que colaboraram com a investigação foge a essa regra e implementa uma outra formar de fazer e pensar a sala de aula. A rotina pedagógica centra-se no estímulo à participação direta e efetiva na vida do grupo, para o crescimento coletivo e individual, no desenvolvimento da consciência de si como sujeito aprendente e integrante de um coletivo prenhe de responsabilidades coletivas, bem como no engajamento na vida em comunidade com planejamento de intervenção/transformação da mesma.

Complementa Niza (2007) sobre o MEM, “um modelo de diferenciação pedagógica em continuado aperfeiçoamento." (p. 38), pautado "num propósito de formação compartilhada e contínua, a que chamamos autoformação cooperada de professores que exercem nos vários ciclos e níveis de ensino, integrando 16 núcleos regionais de actividade, no continente e nas ilhas." (p.38). Um movimento de professores que se associam em torno de uma ruptura 
pedagógica e política com a uniformização e mecanicismo, elementos estes que se comprometem com uma formação acrítica e comprometida com o mercado e não com desenvolvimento pleno do/da indivíduo/sociedade.

Promovem ciclos didáticos em que os métodos dialogam entre si: trabalho de grupo, trabalho individual, trabalho de pesquisa, trabalho com projetos, debate/reflexão sobre a comunidade, construção coletiva do planejamento, em ruptura com a estrutura pedagógica e curricular oficial. A proposta, com bases epistemológicas e muito estudo, é uma inovação comprometida com a transformação social e cultural dos envolvidos. Uma inovação pedagógica que não acontece aliada apenas a uma escolha didático pedagógica, é preciso mais, tem a ver com comprometimento político e social e com uma base sistemática de aprofundamento teórico e experiencial direcionada ao bem comum.

\section{REFERÊNCIAS}

BRUNER, J. Uma Nova Teoria de Aprendizagem. Rio de Janeiro, Edições BLOCH, 1969.

FOLQUE, Maria Assunção. Reconstruindo a cultura em cooperação mediado pela pedagogia para a infância do Movimento da Escola Moderna portuguesa. Perspectiva, Florianópolis, v. 32, n. 3, p. 951 - 975, set./dez. 2014.

FORMOSINHO, Júlia Oliveira. O Modelo Curricular do M.E.M. - Uma Gramática Pedagógica Para a Participação Guiada. Revista Escola Moderna N ${ }^{0} 18 • 5^{\text {a }}$ série• 2003.

FREIRE, Paulo. A importância do ato de ler: em três artigos que se completam. São Paulo: Autores Associados: Cortez, 1989.

FREIRE, Paulo. Pedagogia da Autonomia: saberes necessários à prática educativa. São Paulo: Paz e Terra, 2011.

FRIGOTTO, Gaudêncio. A Produtividade da Escola Improdutiva: um (re)exame das relações entre Educação e estrutura econômico-social capitalista. 9 ed. São Paulo: Cortez, 2010.

LEFEBVRE, Henri. Lógica Formal, Lógica Dialética. Tradução de Carlos Nélson Coutinho. RJ: Civilização Brasileira, 1995.

NIZA, Sérgio. As Práticas Pedagógicas Contra a Exclusão Escolar no Movimento da Escola Moderna. Revista Escola Moderna No $3,5^{\text {a }}$ Série, 2007.

Formação Cooperada: ensaio de auto-avaliação dos efeitos da formação no Projecto Amadora. Educa Movimento da Escola Moderna Portuguesa, Lisboa:1997. Educa. Formação: 4. 
. O Modelo Pré-escolar da Escola Moderna Portuguesa. In: Modelos Curriculares para a Educação de Infância. Porto: Porto Editora, 1996.

PIAGET, J. Psicologia e Pedagogia. S. Paulo, Ed. Forense: 1970.

THOMPSON, E.P. A miséria da teoria, ou um planetário de erros. Tradução de Maltensir Dutra. Rio de Janeiro: Zahar, 1981.

TRINDADE, Rui; COSME, Ariana. Educar e aprender na Escola: Questões, perspectivas e respostas pedagógicas. V. N. de Gaia: Fundação Manuel Leão, 2010. 